\title{
Analyses based on design method of architectural typology in Modern Interpretation -- "Earth Building Commune" as an example
}

\author{
Ying Shi, Sheng Wei \\ School of Architecture, South China University of technology , Guangzhou Guangdong 810008, \\ China
}

key words: architectural typology, prototype, Earth Building Commune, congregated dwelling house

\begin{abstract}
Architectural typology is an age-old concept. It has provided instructive thinking pattern and method of design activity for harmonizing City form and architecture. However, the application of modern architectural typology are not just confined to the continuation of the local image of city and shared memory of history, it has also provided the guidelines of promoting regional characteristic. Some outstanding architectural works emerged in contemporary China have extended the application scope of the typology and contributed to the development of design method based on architectural typology. according to this aspect, the enlightenment of how to continue native regional characteristic for China can be concluded.
\end{abstract}

\section{Concept, Significance and design method of architectural typology}

the "type" in architectural typology is an abstractive concept with vague meaning. it is the commonness extracted from a group, which comes from the result of a certain classification implemented on buildings. The famous theorist Q·D.Quincy once described in” Encyclopedic Dictionary of Architecture" that type does not mean that the copy of thing's image or a perfect imitation, it means a factor concept, this concept is in itself a law of forming model . His description has illuminated that the appearance of "type" aims to extract the common feelings and spirit recognition about historical buildings from human beings, then according to the extraction,The specific architectural model can be formed with guidelines.

The central subject of contemporary architecture research is how to harmonize the relationship between city form and architecture. The growth process of city development can be analogous to organic life in some extent. The emerge of new building, building group or city can be seen as a process of self growth and reproduction of the old city. Based on this point, designers need to create works which own the similar properties with original architecture to continue on the city form. Architectural typology can provided designers a systematic method of classification which aims at categorizing buildings with similar properties. therefore, design method based on architectural typology is significant to designers.

Compared to historicism and symbolism, the application of modern architectural typology in design tends to reveal a kind of improving and moderate attitude to penetrate historic impression into reality. the application of architectural typology can be divided into two steps:1,get the type from the reduction(abstraction) of historical model. 2,conbine the type with specific scene to create relevant specific form. 
the way of design process, which from form to type, then from type to new form, is the concrete embodiment of application of typology in the architectural tectonics. Briefly, it is 1,type selection 2,type processing(reduction).[1]

selecting a proper type for the project may have influence on the essential purpose-----whether can designer make building integrated in the city environment. Sometimes it is also the creative process itself. Type selecting usually based on the fixed image which was bear in mind by the people who own the same cultural background. the selecting type is usually the fixed relation in the group build or some certain architectural motifs. the purpose of type selecting step more tends to emphasize the unity between project and urban environment.

On the basis of type selection, the selected type should be geometric simplified firstly. The purpose of simplification is to convert the particular typology prototype which received from the selection into a universal and abstract architecture type. When designer needs to convey the particularity of project by using architecture, the type usually need to be transformed in order to avoid the same between buildings and the feelings of drab. Thus type conversion process can be seen as a process of alienation.the purpose of type processing step more tends to emphasize the particularity of project.[2]

\section{Analysis of "Earth Building Commune" project based on the perspective of architectural typology}

Overview of "earth building commune" project. Earth Building Commune, Also known as "wan hui lou", is a meaningful attempt which made by URBANUS and VanKe at the end of 2005 in order to help the government solve the problem of urban low-income and cheap housing construction. This project is located in Guangzhou Vanke, south area of four seasons' garden. Covers an area of 9000 square meters, construction area of 12000 square meters, the volume rate is 1.3, can accommodate 1800 people at most. in the form of collection of residential living, storage, store, bazaar, sacrifice, entertainment, and other functions are concentrate in one building volume.[3]Designers strive to solve the current low-income migrant workers' residential issues and try to take advantage of idle land in the highway surrounding the cities as building base at the same time. 


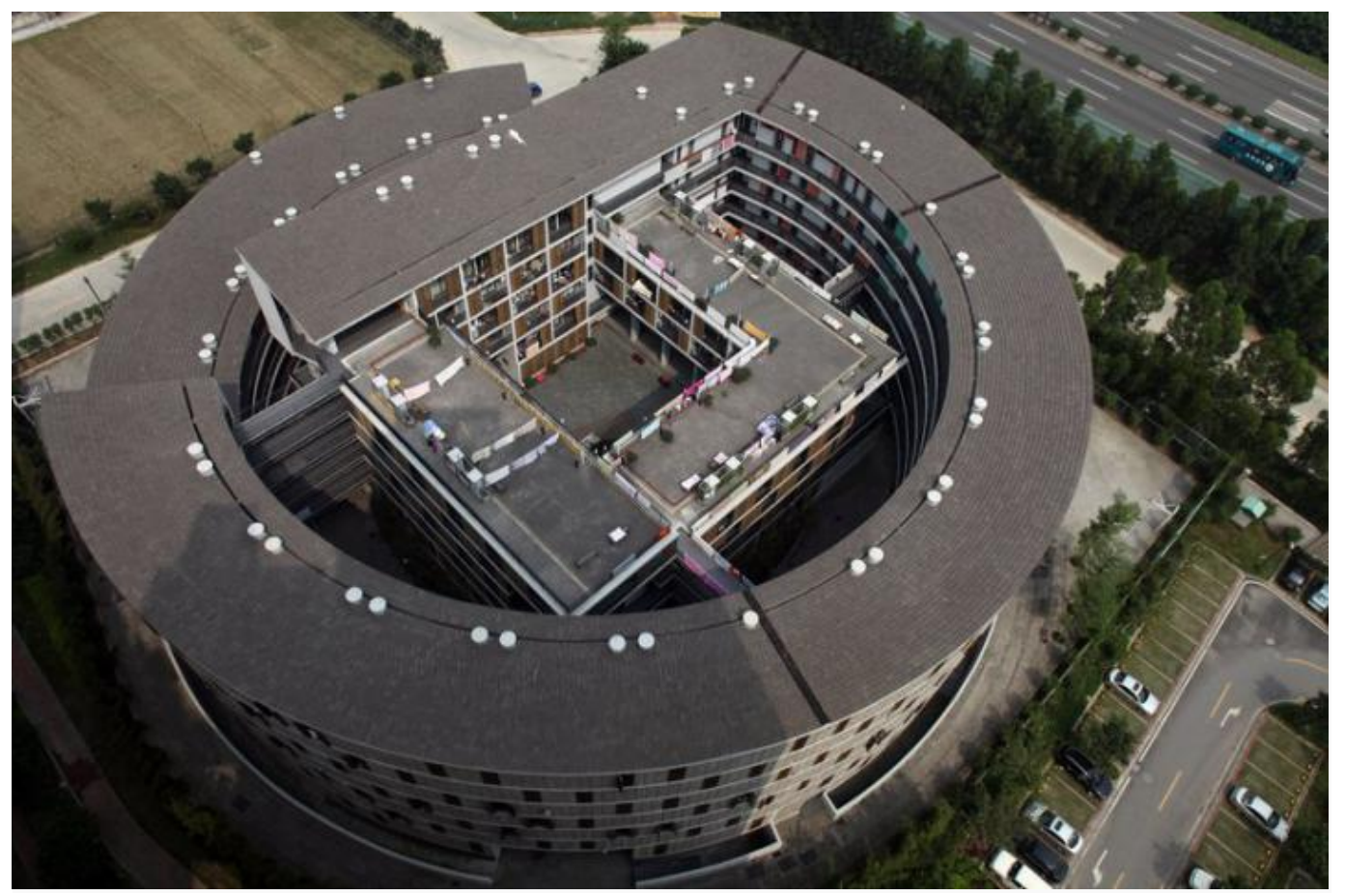

Figure 1 aerial view of Earth Building Commune(Source: collection of ancient art website)

The selection of "Earth Building" type. The type of this project can be traced back to Hakka , which owns several thousand years of developing history. People will unconsciously associate low-income floating people's living issue in urban area with the history of traditional Hakka people's experience of migrating and taking root in the south area. Its traditional architectural image will stimulate the creative thinking about the solutions of present floating people's living and settling issues. To analyses with the perspective of typology ,it is a kind of type selecting behavior which is based on deep understanding of traditional regional architecture and history. Not only did it followed the principle which typology often claims "When face to similar conditions and situations, similar strategies should be adopt" but also had inherited the Hakka architectural culture with leaping time dimension and space dimension simultaneously.since then the application way of architectural typology has been enriched and extended.

\section{the processing(conversion) of "Earth Building " type}

The design of project does not take Hakka architecture prototype a constantly to the old layer for reference, But on the basis of the selected type, the particularities of modern urban development and local geographical environment were taken into consideration during the process of type conversion. The result of this conversion can be summarized as several aspects, they are: (1) conversion of building scale (2) conversion of architectural space (3) conversion of functions.

\section{(1) conversion of building scale}

the volume of traditional Hakka Earth Building, on average, is only about 50 meters in diameter, three to four layers' height,not only is it obviously can't meet the need of the size of the modern residential.but also lead to each residential room's low space utilization rate, which caused by the large deformation due to the small diameter of architectural plane.(figure 2 ) In view of this problem, designers determined to establish 72 meters in plane diameter, 7 floors' height as the building's volume in order to balance the limitations from site and the demand of building's physics environment.(figure 3 ) 


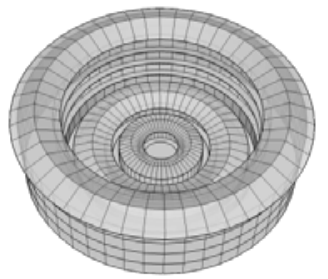

Figure 2 building scale of Hakka Earth Building

(Source: Author self drawing)

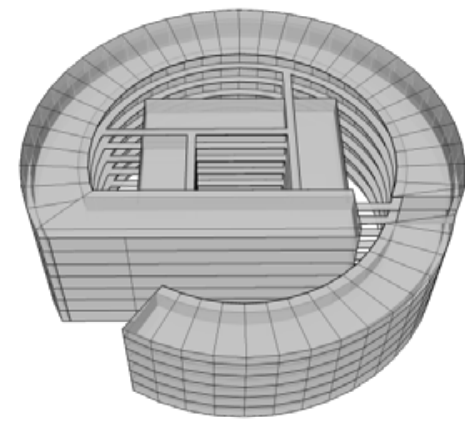

Figure 3 building scale of Hakka Earth Building

(Source: Author self drawing)

\section{(2) conversion of architectural space}

The plane of traditional Hakka Earth Building (here especially round building) is in the form of polycyclic concentric circles to organize traffic stream line. The adjacent outer ring volume and inner ring volume kept a certain distance to meet the needs of the veranda lighting. In general, the outer ring volume(usually residential space) is in form of multi-layer space. While the second outer ring volume to the innermost ring volume are single layer of space to keep the sufficient amount of lighting. However, this kind of traditional pattern can hardly meet the demand of modern life in urban area, especially the demand of the sharing public space in residential building. The outer contour of architectural plane is too closed to match The theme of our age------ Peaceful development and opening to the outside world. (figure4 )

Aimed at solving these problems, the traditional architectural space type must be reasonably converted. Processing techniques of architects are: using e-shape model as the type of plane, the specific approach is opening up a high incision as the entrance so that the closed circular pattern can be broken up(figure 5 ). Secondly, converting the original type of polycyclic concentric circles into outer circle---inner square pattern, the arc-shape interval between round and square edges is more superior than the traditional concentric ring chambers(figure 6 ) in day lighting and ventilation. Thus architects can set inner square ring into multi-layer in order to improve the building volume rate. (figure7 )Finally, the outer circle ring and inner square ring is connected by elevated corridors, which enhance the permeability of the building.

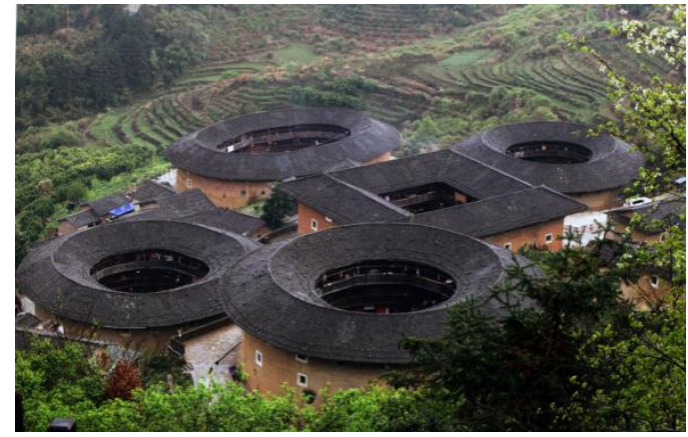

Figure 4 aerial view of Hakka Earth Building (Source: http://m.poco.cn/vision/detail.php?photo_ $\mathrm{id}=3475749$ )

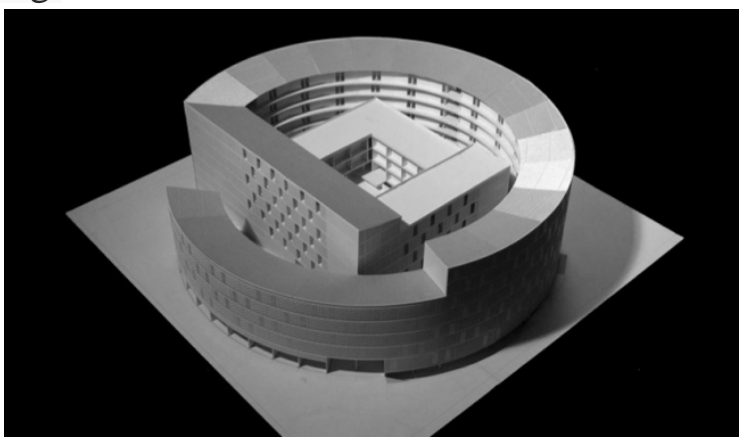

Figure 5model of Earth Building Commune (Source:

http://contemporary.artron.net/20120201/ n215145.html 


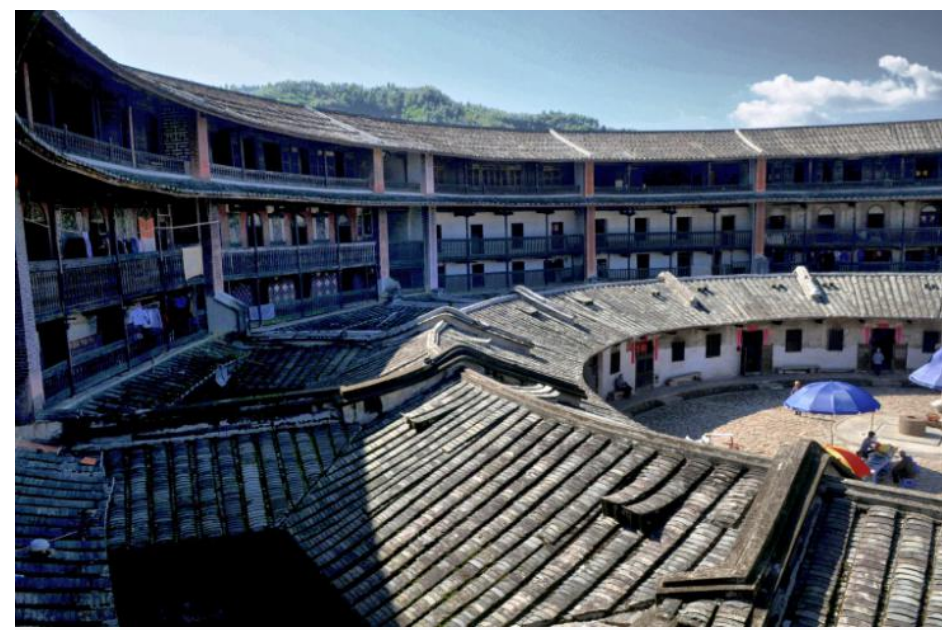

Figure 6Atrium Perspectiveof Hakka Earth Building (Source:

http://liyy1954.blog.163.com/blog/static/95723637201 01010101913419/?hasChannelAdminPriv=true)

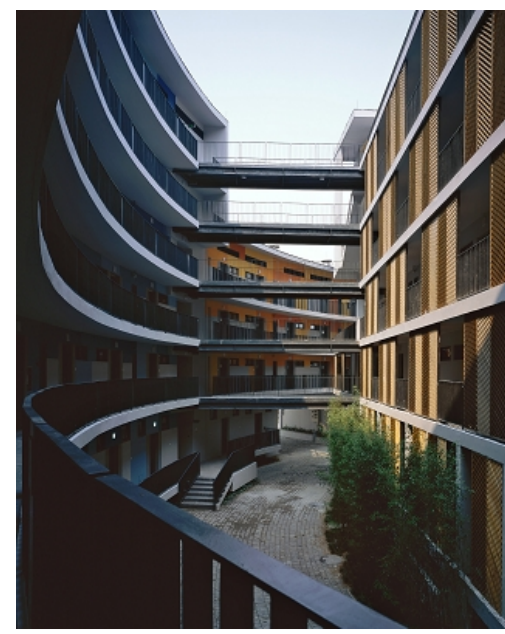

Figure

7Atrium Perspectiveof

Earth

Building Commune (Source: http://blog.sina.com.cn/s/blo g_5fc10d760100dozf.html)

\section{(3) conversion of functions}

" Earth Building Commune " is a compound on the function of community, In every living room there are auxiliary spaces such as independent bathroom, kitchen and store space. Each floor there are public activity spaces, including canteen, shop, library, basketball court and so on, compared with the traditionalHakka Earth Building(figure 8 ), functional transformation and enrichment have satisfied the requirements of modern community life.(figure 9)

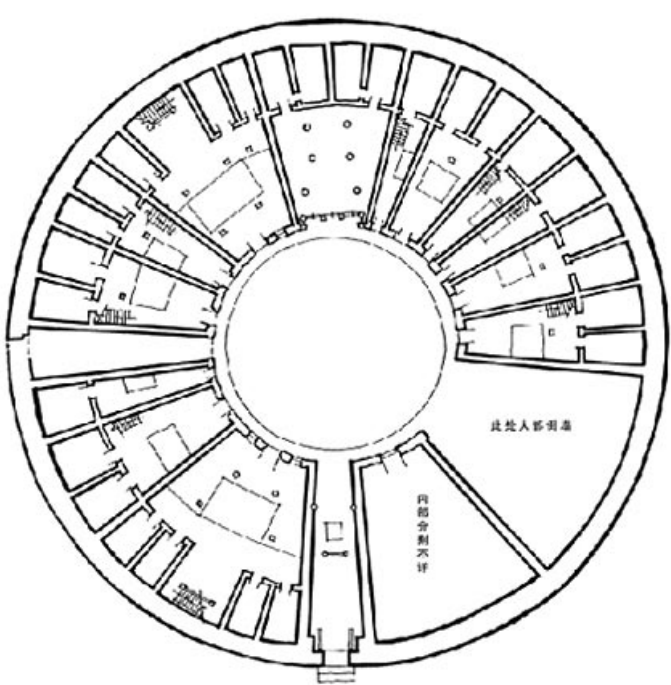

Figure 8 planof Hakka Earth Building (Source:

http://big5.china.com.cn/chinese/zhuanti/ gujian/483768.htm)

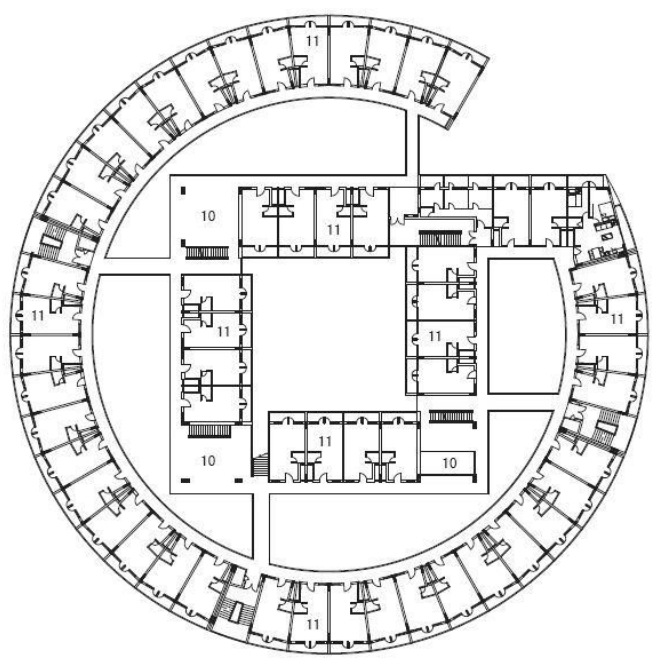

Figure 9 planof Earth Building Commune(Source:

http://www.archi-tag.com/gallery/displayi mage.php?pid=444)

\section{3" Earth Building Commune " sublimation - breakthrough on previous typological method}

The application of architectural typology was confined to continuing city image or the public 
consensus about architectural historical memory. However, " Earth Building Commune ",which was designed by the union of URBANUS and VanKe Group, has provided evidence for the possibilities of extending use of architectural typology. On the basis of deep understanding of traditional buildings' historical development. On the aspect of form, through using the traditional type, designers creatively correlate modern social issue with historical phenomenon across time and space simultaneously. On the aspect of space, through converting the traditional type, the goal of recreating Earth Buildingcommunity space has been achieved.On the aspect of continuing city image. "newEarth Building" has integrated into contemporary urban typical location. designers aimed at picking out the most economical, the most appropriate model through the experiment. This process is the extra inspiration of imagination about city construction.[4]Earth Building with city, green space, city overpass, highway and other scenery from urban environment, choose different one to collage.the experiment is to explore how to use the type of Earth Building to digest the idle land emerged from the process of urban high-speed development.

\section{3, enlightenment from the case" Earth Building Commune" to contemporary architectural design}

Through the creative application of the architectural typology, the project of "Earth Building commune" has enhance typology in the context during the process of theory development. At the same time, the case also provided crucial revelation for contemporary Chinese architectural design to inherit local culture and local characteristics. Traditional architectural forms, such as the case of earth building commune, do not and should not be obsolete or eliminated even though the demands of modern life have changed drastically. If traditional architectural forms, which carried mark of history and culture, can be improved or converted and applied properly, not only will social issues of modern time be solved, but also the past form which carries historical memory can be delivered in the new era and environment.

\section{Conclusion}

To "Earth Building Commune" as a case study, this paper discusses the current the method of how to apply typology to guide the design practice, reached the consensus by people's historical memory and the continuation of city image in a reasonable manner,And on this basis, further discusses how to broaden the use of typology, Not only from the surface of building image to continuation of urban skin texture, and through the deep connotation of the construction of social problems to solve. The hope of contemporary Chinese architecture design in the aspect of promoting local culture sprang out effect.Thus hoping to affect contemporary Chinese architectural design in conveying the local geographical and cultural characteristics.

\section{References}

[1] Wang Lijun, Peng Yigang. To type in Construction -. Typology design methods and architectural form of the constitution [J] ARCHITECTURE, 2001,8

[2] Wang Lijun. architectural typology [M] Tianjin: Tianjin University Press, 2005

[3] Huang Yuan Zhao. 20 Chinese Contemporary Young Architects [M]. Beijing: China Building Industry Press, 2010

[4] Liu xiaodu, Meng Yan.special prize of residential building. - Earthen commune [J] new building, 2009 